\title{
Nonlinear Dynamic Characteristics Analysis of Shift Manipulator for Robot Driver with Multiple Joint Clearance
}

\section{Gang Chen ( $\sim$ gang0418@163.com )}

Nanjing University of Science and Technology https://orcid.org/0000-0002-1126-2087

\section{Xinyao Xu}

Nanjing University of Science and Technology

\section{Research Article}

Keywords: shift manipulator, clearance joint, nonlinear dynamics, characteristics analysis

Posted Date: July 6th, 2021

DOl: https://doi.org/10.21203/rs.3.rs-565645/v1

License: (c) (1) This work is licensed under a Creative Commons Attribution 4.0 International License.

Read Full License 


\title{
Nonlinear Dynamic Characteristics Analysis of Shift Manipulator for Robot Driver with Multiple Joint Clearance
}

\author{
Gang Chen ${ }^{1}$ Xinyao Xu
}

\begin{abstract}
The clearance joint is very important to the nonlinear dynamic characteristics of mechanism. This paper presents a nonlinear dynamic characteristic model of shift manipulator for robot driver based on multiple revolute clearance joints to improve dynamic characteristics. The relative penetration depth and velocity between pin and bushing are obtained by establishing the kinematic model of the shift manipulator with clearance joint. Based on the improved L-N contact force model and the modified Coulomb friction model, the normal contact force and the tangential contact force of clearance joint are analyzed. With full clearance joints, the nonlinear dynamic characteristic model of the shift manipulator for robot driver is established. The nonlinear dynamic characteristic laws of the shift manipulator including the end displacement, velocity, acceleration and active joint driving torque are analyzed by different sizes of clearance joints. And the performance test of the shift manipulator for robot driver is conducted. The results demonstrate that the nonlinear dynamic characteristics are well analyzed and verified through the presented characteristic model with clearance joints.
\end{abstract}

Keywords: shift manipulator; clearance joint; nonlinear dynamics; characteristics analysis

G. Chen

School of Mechanical Engineering,

Nanjing University of Science and Technology, Nanjing 210094, China

e-mail: gang0418@163.com

X.Y.Xu

School of Mechanical Engineering,

Nanjing University of Science and Technology, Nanjing 210094, China

e-mail: xxy_xyl@njust.edu.cn 


\section{Introduction}

Unmanned technology is the development trend of future vehicles. In some special operations, the ground vehicles still use manual gearboxes. It is necessary for vehicles with manual transmission to realize autonomous driving. The robot driver is a new solution for unmanned driving technology [1-4]. Instead of human driver, it uses its manipulators to drive different types of vehicles automatically after conducting vehicle performance self-learning [5]. By being installed in the cab of the vehicle without requiring any significant vehicle modifications, the robot driver turns an ordinary vehicle into an autonomous vehicle [6]. The robot driver is applied in dangerous and harsh driving environments to free human drivers from corresponding working conditions. Robot drivers provide more accurate results than human drivers in some high-risk vehicle testing, including the emission durability testing $[7,8]$.

The shift manipulator is a part of the robot driver. It need carry on shift operation for a long time, which is important for robot driver. In order to better achieve automatic driving of vehicles with manual transmission, many scholars have made investigations about the kinematics and dynamics for different shift manipulators. Chen et al [9] proposed a method for the multibody dynamic modeling of a robot driver including the shift manipulator, but the effect of the clearance joint on the dynamic characteristics is not considered. Lu et al [10] conducted the dynamic analysis for a kind of shift manipulator, but the shift manipulator is just approximated as a simple entity with uniform quality. Yu et al [11] conducted the rigid-flexible coupling characteristic analysis of a shift manipulator, but the clearance joint is ignored and the contact between the components is only replaced by ideal constraints. Mizutani et al [12] designed a robot driver considering the shift changes, but the dynamic model is too simple and the effect of clearance joint during gear shifting is not reflected. Chu et al [13] proposed a method for velocity control of electric vehicle driving robot including the shift manipulator, but only the longitudinal vehicle velocity is verified and the characteristics of the shifting manipulator is not satisfactory. Zhou et al [14] proposed a simulation method of shift load fluctuation and analyzed the characteristics of the shift manipulator, but the influence of dynamic characteristics caused by the change of clearance joint is not considered. Yu et al [15] designed a pedal actuator of driver robot based on flexible manipulator, but only ideal joint is considered and the model of clearance joint is not established. Few researches in existed paper for the nonlinear dynamic characteristics of clearance joint for the shift manipulator, which have an essential influence on the shifting operation.

The complexity of dynamic model and characteristic analysis of mechanical structures are increased by the existence of clearance joints[16-22]. While the joints are simplified to complete joints without clearance in current research, which change the dynamic characteristics of the shift manipulator [23-28]. In order to improve dynamic characteristics, various approaches are presented to study the clearance joint. And the contact force model [29-33] and the friction model [34-36] are mainly used in the current research on clearance joint. Chen et al [37] and Guo et al [38] respectively analyzed the dynamic characteristics through the dynamic model of machine with clearance joint, but the presented model is just a simple linkage mechanism. Zhao et al [39] proposed a new analysis approach for a planar model based on the clearance joint, but only a single clearance joint is considered. Wang et al [40] and Tang et al [41] respectively presented two approaches of dynamic model with clearance joint, but deep dynamic characteristic analysis of the 
clearance joint is not conducted. Most of the research on clearance joint is limited to simple mechanisms and single clearance joint. There is a lack of research on multiple clearance joints. Khashaba et al [42] and Song et al [43] respectively performed a dynamic model of mechanisms with multiple clearance joints, but the nonlinear dynamic characteristic analysis of the model is not conducted. Sun et al [44] and Zhao et al [45] analyzed the characteristics based on a dynamic model of mechanism with clearance joint, but other nonlinear factors are not considered. $\mathrm{Ma}$ et al [46] and $\mathrm{Pi}$ et al [47] both performed dynamic analysis through a mechanism with multiple clearance joints, but the results are too simple and other characteristics are not reflected. Few nonlinear factors are considered in current characteristic analysis and the analysis of nonlinear dynamic characteristics is incomplete.

Considering these limitations, in this paper, a characteristic model for nonlinear dynamic analysis of shift manipulator for robot driver is presented. The clearance joint is analyzed based on the contact force model and friction model. The nonlinear dynamic characteristic model is established with full revolute clearance joints. The multiple nonlinear dynamic characteristics are conducted by giving different sizes of clearance joints. The effectiveness of characteristic model is verified by the results of performance test. The nonlinear dynamic analysis of shift manipulator for high dynamic characteristics is conducted through the presented model.

The remainder of this paper is organized as follows. In Sect. 2, the clearance joint of shift manipulator is analyzed, and its kinematic model is established. In Sect. 3, the contact force is analyzed through the improved L-N contact force model and the modified Coulomb friction model. In Sect. 4, the nonlinear dynamic characteristic model of the shift manipulator with multiple clearance joints is established. In Sect. 5, the characteristic analysis and performance test of the shift manipulator are conducted. Finally, the conclusions are drawn in Sect. 5.

\section{Kinematic model of clearance joint for shift manipulator}

\subsection{Structure description}

The three-dimensional model of the vehicle robot driver and the shift manipulator investigated in this paper are shown in Fig. 1 and Fig. 2. The mechanical structure of the vehicle robot driver is primarily composed of a shift manipulator, a brake mechanical leg, a throttle mechanical leg, and a clutch mechanical leg for controlling gear lever, brake pedal, throttle pedal and clutch pedal respectively. The clutch mechanical leg is removed when the robot driver is applying in the automatic transmission vehicle.

In order to be used in both a manual transmission vehicle and an automatic transmission vehicle, the shift manipulator is designed to have two degrees of freedom, which task workspace is a plane area. As shown in Fig. 2, the shift manipulator consists of a base, the handle link and three chains including chain 1, chain 2, chain 3 from right to left. Each chain contains two links and three revolute joints. The three chains are connected by one common revolute joint. The revolute joints of chain 2 and chain 3 connected to the base are active joints. One end of the handle link is fixed at the end of chain 1, and the other end is used to connect and drive the shift lever. In order to save the installation room for the mechanism in the 
vertical direction and improve the positioning precision, the shift manipulator is actuated by two linear motors instead of two rotary motors. There is a crank-slider mechanism between each active joint and the corresponding linear motor for converting the linear input into the rotational input.

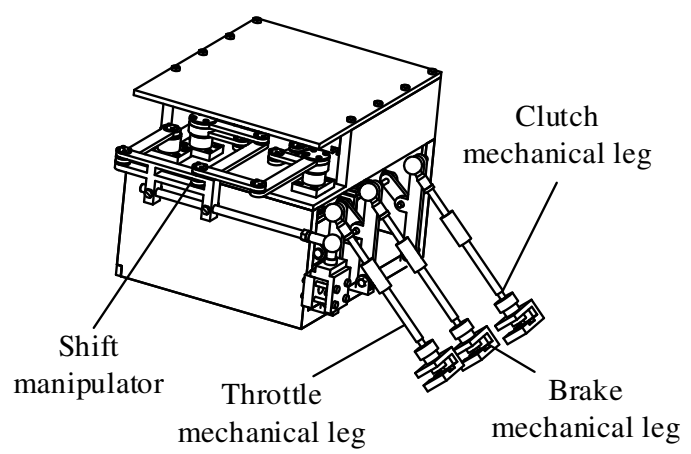

Fig. 1 Mechanical structure of robot driver

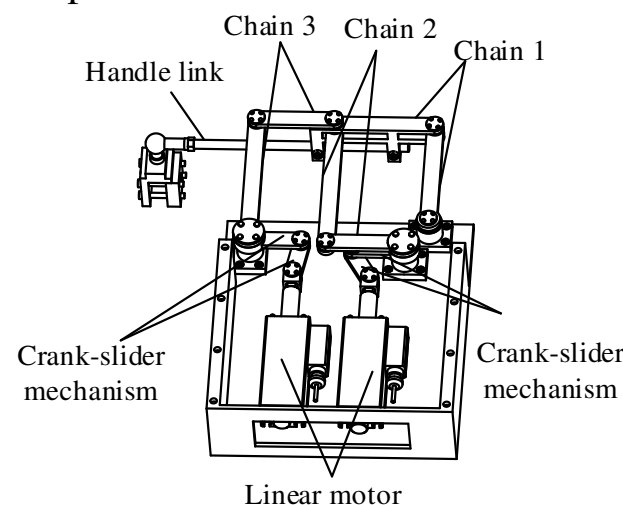

Fig. 2 Structure sketch of the parallel shift manipulator

2.2 kinematic analysis of clearance joint

The revolute clearance joint is introduced into the shift manipulator and the model of revolute clearance joint is shown in Fig.3. $R_{i}$ and $R_{j}$ are represent the radius of bushing and pin, respectively. The size of clearance joint is expressed as $c=R_{i}-R_{j}$. The pin moves in the bushing without constraints due to the existence of clearance joints. The relative motion phase between the pin and bushing in joint are divided into three types including continuous contact phase, free flight phase and collision phase, as shown in Fig.3(b).

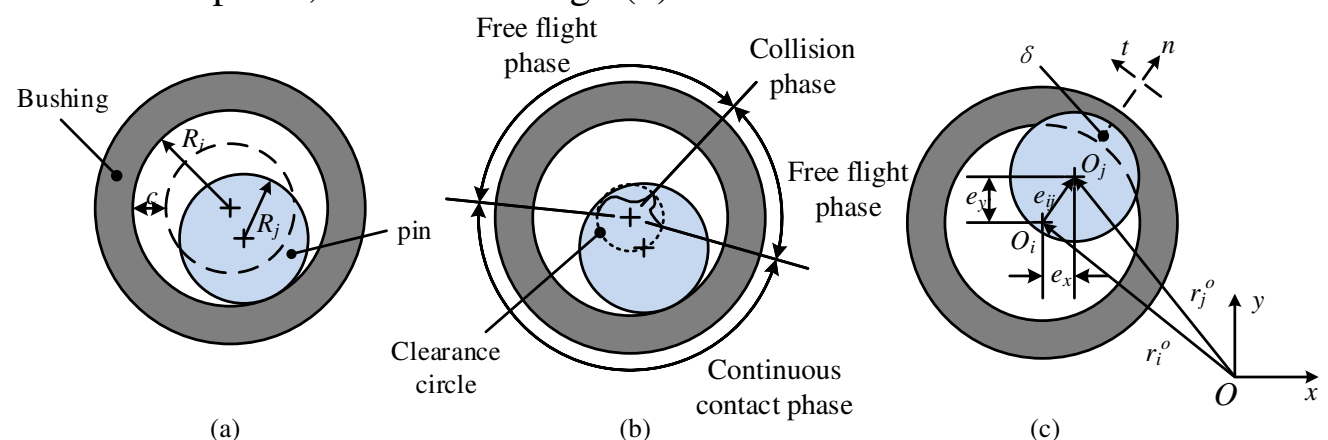

(a)

(b)

(c)

Fig. 3 Model of the clearance joint: a diagram of clearance joint, $\mathbf{b}$ motion of pin, $\mathbf{c}$ mathematical model

The mathematical model of clearance joint is shown in Fig.3(c), $O_{i}$ and $O_{j}$ are represent the center coordinates of bushing and pin, respectively. $\boldsymbol{r}_{i}^{o}$ and $\boldsymbol{r}_{j}^{o}$ respectively represent the positions of bushing and pin, which are linked by a revolute clearance joint in the global inertia coordinate $O-x y$. Thus, the eccentricity vector $e_{i j}$ is defined as the vector connecting the centers of bushing and pin, which is expressed as

$$
\boldsymbol{e}_{i j}=\boldsymbol{r}_{j}^{o}-\boldsymbol{r}_{i}^{o}
$$

Then the size of the clearance vector is obtained as

$$
e_{i j}=\sqrt{e_{x}^{2}+e_{y}^{2}}
$$


The unit normal vector at the point of contact between bushing and pin is obtained as

$$
\boldsymbol{n}=\frac{\boldsymbol{e}_{i j}}{\boldsymbol{e}_{i j}}
$$

Eq. (3) is expanded as

$$
\boldsymbol{n}=\frac{\boldsymbol{e}_{i j}}{\sqrt{e_{x}^{2}+e_{y}^{2}}}
$$

The collision between bushing and pin is described through Eq. (1) to Eq. (4), and the contact deformation depth is obtained as

$$
\delta=e_{i j}-c
$$

where $c$ is the size of clearance joint.

Therefore, Eq. 5 is used to determine whether there is contact between bushing and pin. The motion contact condition of bushing and pin is determined by

$$
\delta=e_{i j}-c=\sqrt{e_{x}^{2}+e_{y}^{2}} \geq 0
$$

The relative motion phase of bushing and pin is determined through Eq. (6). The clearance joint is in free flight phase if $\delta<0$. The clearance joint is in continuous contact phase if $\delta=0$. The clearance joint is in collision phase if $\delta>0$.

Meanwhile, in order to calculate the energy loss during the contact between bushing and pin of the robot driver, the relative velocity of the contact between bushing and pin needs to be calculated.

The normal and tangential velocity of the collision contact point between bushing and pin are obtained as

$$
\begin{aligned}
& \boldsymbol{v}_{n}=\dot{\delta}^{T} \boldsymbol{n} \\
& \boldsymbol{v}_{t}=\dot{\delta}^{T} \boldsymbol{t}
\end{aligned}
$$

where the unit tangential vector $\boldsymbol{t}$ is obtained by rotating $\boldsymbol{n}$ in the clockwise direction as $90^{\circ}$.

\section{Contact force analysis of clearance joint for shift manipulator}

For the clearance joint of shift manipulator for robot driver, the force of contact point $\boldsymbol{F}_{c}$ is made up by normal contact force $\boldsymbol{F}_{n}$ and tangential friction force $\boldsymbol{F}_{t}$ during collision. The clearance joint is in free flight phase when $\boldsymbol{F}_{c}=0$. While when the clearance joint is in continuous contact phase and collision phase, the relational equation is obtained as

$$
\boldsymbol{F}_{c}=\boldsymbol{F}_{n}+\boldsymbol{F}_{t}
$$

In order to unify the expression, the step function is introduced as

$$
u(\delta)= \begin{cases}0 & \delta<0 \\ 1 & \delta \geq 0\end{cases}
$$

The contact force of clearance joint $\boldsymbol{F}_{c}$ is obtained as

$$
\boldsymbol{F}_{c}=u(\delta)\left(\boldsymbol{F}_{n}+\boldsymbol{F}_{t}\right)
$$

3.1 Normal contact force 
In order to describe the contact force between bushing and pin, the elastic modulus and damping of bushing and pin need to be considered to calculate the contact force. The improved L-N nonlinear contact force model is used in this paper. In this model, a nonlinear stiffness coefficient is proposed based on the contact theory. The nonlinear stiffness coefficient is more realistic through changing with the process of working conditions. Besides, a modified damping coefficient is added to the model, which is not limited by the restitution coefficient.

The compound modulus $E^{*}$ is obtained as

$$
E^{*}=\left(\frac{1-v_{i}^{2}}{E_{i}}+\frac{1-v_{j}^{2}}{E_{j}}\right)^{-1}
$$

where $v_{i}$ and $v_{j}$ respectively represent Poisson ratio of bushing and pin, $E_{i}$ and $E_{j}$ respectively represent Young's modulus of bushing and pin.

Then, the nonlinear stiffness coefficient $K_{n}$ is obtained as

$$
K_{n}=\frac{\pi E^{*} L \delta^{n}}{2} \sqrt{\left(\frac{1}{2(c+\delta)}\right)}
$$

where $L$ is the length of pin, $n=1.5$.

The modified damping coefficient $D_{\bmod }$ is obtained as

$$
D_{\text {mod }}=\frac{3}{4} \frac{K_{n}\left(1-c_{e}^{2}\right) e^{2\left(1-c_{e}\right)} \delta^{n}}{\dot{\delta}_{0}}
$$

where $c_{e}$ is the coefficient of restitution, $\dot{\delta}_{0}$ is the initial collision velocity.

Based on the improved L-N nonlinear contact force model, the normal contact force $\boldsymbol{F}_{n}$ is obtained as

$$
\boldsymbol{F}_{n}=K_{n} \delta^{n}+D_{\text {mod }} \dot{\delta}
$$

where $\dot{\delta}$ is the relative penetration velocity.

\subsection{Tangential friction force}

The numerical definition of the Coulomb friction law is difficult when the relative tangential velocity is close to zero. In order to reduce difficulty, the modified Coulomb friction model is used to describe the tangential friction force at the clearance joint of shift manipulator for robot driver.

The dynamic correction factor $c_{d}$ is introduced as

$$
\left\{\begin{array}{lc}
0 & \left|\boldsymbol{v}_{t}\right|<v_{s} \\
\frac{\left|\boldsymbol{v}_{t}\right|-v_{s}}{v_{d}-v_{s}} & v_{s} \leq\left|\boldsymbol{v}_{t}\right| \leq v_{d} \\
1 & \left|\boldsymbol{v}_{t}\right|>v_{d}
\end{array}\right.
$$

where $v_{s}$ and $v_{d}$ are minimum and maximum critical velocity, respectively.

Then, the tangential friction force is obtained as

$$
\boldsymbol{F}_{t}=-c_{f} c_{d} \boldsymbol{F}_{n} \frac{\boldsymbol{v}_{t}}{\left|\boldsymbol{v}_{t}\right|}
$$

where $c_{f}$ is the friction coefficient, $v_{t}$ is the relative sliding velocity. 


\section{Nonlinear dynamic characteristic model of shift manipulator with clearance joints}

For robot driver, the schematic diagram of shift manipulator with clearance joints is shown in Fig.4. The shift manipulator is composed of six links $l_{i j}(i=1,2,3 ; j=1,2)$ and a handle link $l_{p c}$. And the handle link $l_{p c}$ is fix with the link $l_{12}$. Joints $A_{i}(i=1,2,3)$ are regarded as ideal joints, while joints $B_{i}(i=1,2,3)$ and the two joints $C_{2}$ and $C_{3}$ of the compound joint $C$ are regarded as clearance joints. Joint $C_{2}$ is the connecting joint of link $l_{12}$ and link $l_{22}$, and joint $C_{3}$ is the connecting joint of link $l_{12}$ and link $l_{32}$. The link $l_{21}$ and the link $l_{31}$ are the gear selection rocker and the gear rocker, respectively. Joint $A_{2}$ and joint $A_{3}$ are drive joints. The shift manipulator is designed to have two degrees of freedom in the $x$ and $y$ directions based on the fixed global reference coordinate system $O\left(A_{1}\right)-x y$.

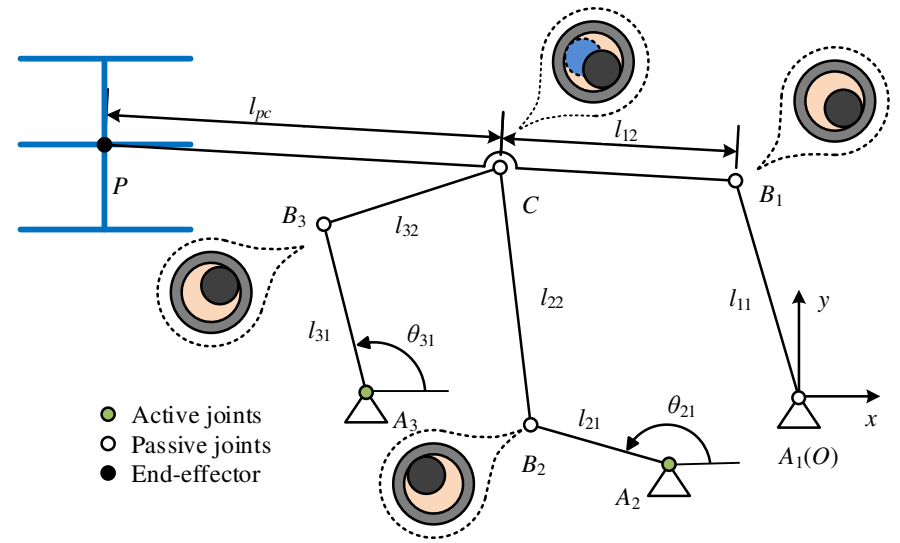

Fig. 4 Schematic diagram of shift manipulator with clearance joints

In the global coordinate system $O\left(A_{1}\right)-x y, x_{i j}$ and $y_{i j}$ are defined as the abscissa and ordinate positions of the centroid of the link $l_{i j}(i=1,2,3 ; j=1,2)$, $x_{p c}$ and $y_{p c}$ are defined as the position of the centroid of the handle link $l_{p c} . \theta_{i j}$ is the angle between the local coordinate system of the link $l_{i j}(i=1,2,3 ; j=1,2)$ and the global coordinate system, $\theta_{p c}$ is the angle between the local coordinate system of the handle link $l_{p c}$ and the global coordinate system.

Thus, the generalized displacement of the shift manipulator for robot driver are defined as

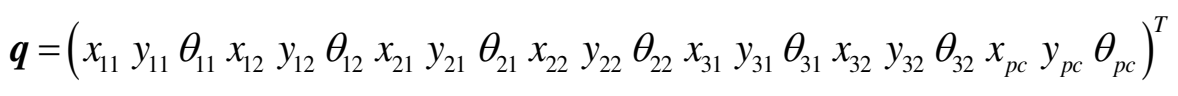

And the generalized velocity and generalized acceleration of the shift manipulator are represented by $\dot{\boldsymbol{q}}$ and $\ddot{\boldsymbol{q}}$, respectively.

When the clearance joints of the shift manipulator are not considered, each revolute joint has two equations to constrain. So the shift manipulator constraint equation is obtained as 


$$
\boldsymbol{\Phi}=\left[\begin{array}{c}
x_{11}-r_{11} \cos \theta_{11} \\
y_{11}-r_{11} \sin \theta_{11} \\
x_{12}-r_{12} \cos \theta_{12}-l_{11} \cos \theta_{11} \\
y_{12}-r_{12} \sin \theta_{12}-l_{11} \sin \theta_{11} \\
x_{21}-r_{21} \cos \theta_{21}-x_{A 1} \\
y_{21}-r_{21} \sin \theta_{21}-y_{A 1} \\
x_{22}-r_{22} \cos \theta_{22}-l_{21} \cos \theta_{21}-x_{A 2} \\
y_{22}-r_{22} \sin \theta_{22}-l_{21} \sin \theta_{21}-y_{A 2} \\
x_{31}-r_{31} \cos \theta_{31}-x_{A 2} \\
y_{31}-r_{31} \sin \theta_{31}-y_{A 2} \\
x_{32}-r_{32} \cos \theta_{32}-l_{31} \cos \theta_{31}-x_{A 3} \\
y_{32}-r_{32} \sin \theta_{32}-l_{31} \sin \theta_{31}-y_{A 3} \\
l_{11} \cos \theta_{11}+l_{12} \cos \theta_{12}-l_{22} \cos \theta_{22}-l_{21} \cos \theta_{21}-x_{A 2} \\
l_{11} \sin \theta_{11}+l_{12} \sin \theta_{12}-l_{22} \sin \theta_{22}-l_{21} \sin \theta_{21}-y_{A 2} \\
l_{11} \cos \theta_{11}+l_{12} \cos \theta_{12}-l_{32} \cos \theta_{32}-l_{31} \cos \theta_{31}-x_{A 3} \\
l_{11} \sin \theta_{11}+l_{12} \sin \theta_{12}-l_{32} \sin \theta_{32}-l_{31} \sin \theta_{31}-y_{A 3} \\
x_{p c}-r_{p c} \cos \theta_{p c}-l_{12} \cos \theta_{12}-l_{11} \cos \theta_{11} \\
y_{p c}-r_{p c} \sin \theta_{p c}-l_{12} \sin \theta_{12}-l_{11} \sin \theta_{11} \\
\theta_{p c}-\theta_{12}
\end{array}\right]=\mathbf{O}
$$

where $r_{i j}$ and $r_{p c}$ respectively represent the distance from the centroid of the link $l_{i j}(i=1,2,3 ; j=1,2)$ and the handle link $l_{p c}$ to the end point of joint, $x_{A 2}$ and $x_{A 3}$ respectively represent the lateral distance from joint $A_{2}$ and joint $A_{3}$ to the origin of the global coordinate system, $y_{A 2}$ and $y_{A 3}$ respectively represent the longitudinal distance from joint $A_{2}$ and joint $A_{3}$ to the origin of the global coordinate system.

The absolute coordinate number 21 is subtracted from the constraint equation number 19 , and the degree of freedom of the shifting manipulator system is 2 . The Jacobian matrix $\boldsymbol{\Phi}_{q}$ and matrix $\boldsymbol{\xi}$ of the shift manipulator are obtained by differentiating the constraint equations of the shift manipulator to $\boldsymbol{q}$ and $t$.

The Jacobian matrix $\boldsymbol{\Phi}_{q}$ of shift manipulator is obtained as

\begin{tabular}{|c|c|c|c|c|c|c|c|c|c|c|c|c|c|c|c|c|c|c|c|c|}
\hline 1 & 0 & $r_{11} \sin \theta_{11}$ & 0 & 0 & 0 & 0 & 0 & 0 & 0 & 0 & 0 & 0 & 0 & 0 & 0 & 0 & 0 & 0 & 0 & 0 \\
\hline 0 & 1 & $-r_{11} \cos \theta_{11}$ & 0 & 0 & 0 & 0 & 0 & 0 & 0 & 0 & 0 & 0 & 0 & 0 & 0 & 0 & 0 & 0 & 0 & 0 \\
\hline 0 & 0 & $l_{11} \sin \theta_{11}$ & 1 & 0 & $r_{12} \sin \theta_{12}$ & 0 & 0 & 0 & 0 & 0 & 0 & 0 & 0 & 0 & 0 & 0 & 0 & 0 & 0 & 0 \\
\hline 0 & 0 & $-l_{11} \cos \theta_{11}$ & 0 & 1 & $-r_{12} \cos \theta_{12}$ & 0 & 0 & 0 & 0 & 0 & 0 & 0 & 0 & 0 & 0 & 0 & 0 & 0 & 0 & 0 \\
\hline 0 & 0 & 0 & 0 & 0 & 0 & 1 & 0 & $r_{21} \sin \theta_{21}$ & 0 & 0 & 0 & 0 & 0 & 0 & 0 & 0 & 0 & 0 & 0 & 0 \\
\hline 0 & 0 & 0 & 0 & 0 & 0 & 0 & 1 & $-r_{21} \cos \theta_{21}$ & 0 & 0 & 0 & 0 & 0 & 0 & 0 & 0 & 0 & 0 & 0 & 0 \\
\hline 0 & 0 & 0 & 0 & 0 & 0 & 0 & 0 & $l_{21} \sin \theta_{21}$ & 1 & 0 & $r_{22} \sin \theta_{22}$ & 0 & 0 & 0 & 0 & 0 & 0 & 0 & 0 & 0 \\
\hline 0 & 0 & 0 & 0 & 0 & 0 & 0 & 0 & $-l_{21} \cos \theta_{21}$ & 0 & 1 & $-r_{22} \cos \theta_{22}$ & 0 & 0 & 0 & 0 & 0 & 0 & 0 & 0 & 0 \\
\hline 0 & 0 & 0 & 0 & 0 & 0 & 0 & 0 & 0 & 0 & 0 & 0 & 1 & 0 & $r_{31} \sin \theta_{31}$ & 0 & 0 & 0 & 0 & 0 & 0 \\
\hline 0 & 0 & 0 & 0 & 0 & 0 & 0 & 0 & 0 & 0 & 0 & 0 & 0 & 1 & $-r_{31} \cos \theta_{31}$ & 0 & 0 & 0 & 0 & 0 & 0 \\
\hline 0 & 0 & 0 & 0 & 0 & 0 & 0 & 0 & 0 & 0 & 0 & 0 & 0 & 0 & $l_{31} \sin \theta_{31}$ & 1 & 0 & $r_{32} \sin \theta_{32}$ & 0 & 0 & 0 \\
\hline 0 & 0 & 0 & 0 & 0 & 0 & 0 & 0 & 0 & 0 & 0 & 0 & 0 & 0 & $-l_{31} \cos \theta_{31}$ & 0 & 1 & $-r_{32} \cos \theta_{32}$ & 0 & 0 & 0 \\
\hline 0 & 0 & $-l_{11} \sin \theta_{11}$ & 0 & 0 & $-l_{12} \sin \theta_{12}$ & 0 & 0 & $l_{21} \sin \theta_{21}$ & 0 & 0 & $l_{22} \sin \theta_{22}$ & 0 & 0 & 0 & 0 & 0 & 0 & 0 & 0 & 0 \\
\hline 0 & 0 & $l_{11} \cos \theta_{11}$ & 0 & 0 & $l_{12} \cos \theta_{12}$ & 0 & 0 & $-l_{21} \cos \theta_{21}$ & 0 & 0 & $-l_{22} \cos \theta_{22}$ & 0 & 0 & 0 & 0 & 0 & 0 & 0 & 0 & 0 \\
\hline 0 & 0 & $-l_{11} \sin \theta_{11}$ & 0 & 0 & $-l_{12} \sin \theta_{12}$ & 0 & 0 & 0 & 0 & 0 & 0 & 0 & 0 & $l_{31} \sin \theta_{31}$ & 0 & 0 & $l_{32} \sin \theta_{32}$ & 0 & 0 & 0 \\
\hline 0 & 0 & $l_{11} \cos \theta_{11}$ & 0 & 0 & $l_{12} \cos \theta_{12}$ & 0 & 0 & 0 & 0 & 0 & 0 & 0 & 0 & $-l_{31} \cos \theta_{31}$ & 0 & 0 & $-l_{32} \cos \theta_{32}$ & 0 & 0 & 0 \\
\hline 0 & 0 & $l_{11} \sin \theta_{11}$ & 0 & 0 & $l_{12} \sin \theta_{12}$ & 0 & 0 & 0 & 0 & 0 & 0 & 0 & 0 & 0 & 0 & 0 & 0 & 1 & 0 & $r_{p c} \sin \theta_{p c}$ \\
\hline 0 & 0 & $-l_{11} \cos \theta_{11}$ & 0 & 0 & $-l_{12} \cos \theta_{12}$ & 0 & 0 & 0 & 0 & 0 & 0 & 0 & 0 & 0 & 0 & 0 & 0 & 0 & 1 & $-r_{p c} \cos \theta_{p c}$ \\
\hline 0 & 0 & 0 & 0 & 0 & -1 & 0 & 0 & 0 & 0 & 0 & 0 & 0 & 0 & 0 & 0 & 0 & 0 & & 0 & 1 \\
\hline
\end{tabular}


$\boldsymbol{\Phi}_{t}=\boldsymbol{O}$

The matrix $\xi$ of shift manipulator is obtained as

$$
\boldsymbol{\xi}=-\left[\left(\boldsymbol{\Phi}_{q} \dot{\boldsymbol{q}}\right)_{q} \dot{\boldsymbol{q}}+2 \boldsymbol{\Phi}_{q t} \dot{\boldsymbol{q}}+\boldsymbol{\Phi}_{t t}\right]
$$

Eq. (22) is expanded as

$$
\boldsymbol{\xi}=-\left[\begin{array}{c}
r_{11} \dot{\theta}_{11}^{2} \cos \theta_{11} \\
r_{11} \dot{\theta}_{11}^{2} \sin \theta_{11} \\
l_{11} \dot{\theta}_{11}^{2} \cos \theta_{11}+r_{12} \dot{\theta}_{12}^{2} \cos \theta_{12} \\
l_{11} \dot{\theta}_{11}^{2} \sin \theta_{11}+r_{12} \dot{\theta}_{12}^{2} \sin \theta_{12} \\
r_{21} \dot{\theta}_{21}^{2} \cos \theta_{21} \\
r_{21} \dot{\theta}_{21}^{2} \sin \theta_{21} \\
l_{21} \dot{\theta}_{21}^{2} \cos \theta_{21}+r_{22} \dot{\theta}_{22}^{2} \cos \theta_{22} \\
l_{21} \dot{\theta}_{21}^{2} \sin \theta_{21}+r_{22} \dot{\theta}_{22}^{2} \sin \theta_{22} \\
r_{31} \dot{\theta}_{31}^{2} \cos \theta_{31} \\
r_{31} \dot{\theta}_{31}^{2} \sin \theta_{31} \\
l_{31} \dot{\theta}_{31}^{2} \cos \theta_{31}+r_{32} \dot{\theta}_{32}^{2} \cos \theta_{32} \\
l_{31} \dot{\theta}_{31}^{2} \sin \theta_{31}+r_{32} \dot{\theta}_{32}^{2} \sin \theta_{32} \\
-l_{11} \dot{\theta}_{11}^{2} \cos \theta_{11}-l_{12} \dot{\theta}_{12}^{2} \cos \theta_{12}+l_{21} \dot{\theta}_{21}^{2} \cos \theta_{21}+l_{22} \dot{\theta}_{22}^{2} \cos \theta_{22} \\
-l_{11} \dot{\theta}_{11}^{2} \sin \theta_{11}-l_{12} \dot{\theta}_{12}^{2} \sin \theta_{12}+l_{21} \dot{\theta}_{21}^{2} \sin \theta_{21}+l_{22} \dot{\theta}_{22}^{2} \sin \theta_{22} \\
-l_{11} \dot{\theta}_{11}^{2} \cos \theta_{11}-l_{12} \dot{\theta}_{12}^{2} \cos \theta_{12}+l_{31} \dot{\theta}_{31}^{2} \cos \theta_{31}+l_{32} \dot{\theta}_{32}^{2} \cos \theta_{32} \\
-l_{11} \dot{\theta}_{11}^{2} \sin \theta_{11}-l_{12} \dot{\theta}_{12}^{2} \sin \theta_{12}+l_{31} \dot{\theta}_{31}^{2} \sin \theta_{31}+l_{32} \dot{\theta}_{32}^{2} \sin \theta_{32} \\
l_{11} \dot{\theta}_{11}^{2} \cos \theta_{11}+l_{12} \dot{\theta}_{12}^{2} \cos \theta_{12}+r_{p c} \dot{\theta}_{p c}^{2} \cos \theta_{p c} \\
l_{11} \dot{\theta}_{11}^{2} \sin \theta_{11}+l_{12} \dot{\theta}_{12}^{2} \sin \theta_{12}+r_{p c} \dot{\theta}_{p c}^{2} \sin \theta_{p c} \\
0 \\
0
\end{array}\right]
$$

Therefore, the velocity constraint equation of the shift manipulator is obtained as

$$
\boldsymbol{\Phi}_{q} \dot{\boldsymbol{q}}=\mathbf{0}
$$

The acceleration constraint equation of the shift manipulator is obtained as

$$
\boldsymbol{\Phi}_{q} \ddot{\boldsymbol{q}}=\boldsymbol{\xi}
$$

The ideal rigid body dynamic characteristic model of the shift manipulator for robot driver is established based on the Newton-Euler method, which is obtained as

$$
\boldsymbol{M} \ddot{\boldsymbol{q}}=\boldsymbol{g}
$$

where $\boldsymbol{M}$ is the quality matrix of the shift manipulator, $\boldsymbol{g}$ is the generalized external force of the shift manipulator without clearance joint, $\boldsymbol{M}=\operatorname{diag}\left(m_{i j}, m_{i j}, I_{i j}, m_{p c}, m_{p c}, I_{p c}\right)(i=1,2,3 ; j=1,2)$.

When the clearance joints of the shift manipulator are considered, geometric constraints are transformed into force constraints. It means that the kinematic constraints of joints are removed in the constraint equations of shift manipulator and joints are constrained through the form of joint contact force. The two degrees of freedom at each joint of the shift manipulator when this clearance joint is considered. So the number of system constraint equations is reduced accordingly. 
The dynamic characteristic model of the shift manipulator for robot driver with clearance joints is established as

$$
\boldsymbol{M} \ddot{\boldsymbol{q}}+\boldsymbol{\Phi}_{q}^{T} \boldsymbol{\lambda}=\boldsymbol{g}+\boldsymbol{g}_{c}
$$

where $\boldsymbol{g}_{c}$ is the equal force of the collision force and friction force caused by the clearance joint of the shift manipulator, $\lambda$ is the Lagrangian multiplier column vector, which means the interaction force between the joint elements of the shift manipulator,

Solving simultaneously Eq. (27) and the kinematic constraint equations, Eq. (28) is obtained as

$$
\left[\begin{array}{cc}
\boldsymbol{M} & \boldsymbol{\Phi}_{q}^{T} \\
\boldsymbol{\Phi}_{q} & \boldsymbol{0}
\end{array}\right]\left[\begin{array}{c}
\ddot{\boldsymbol{q}} \\
\boldsymbol{\lambda}
\end{array}\right]=\left[\begin{array}{c}
\boldsymbol{g}+\boldsymbol{g}_{c} \\
\boldsymbol{\xi}
\end{array}\right]
$$

The equal force of the collision force and friction force caused by the clearance joint of the shift manipulator $\boldsymbol{g}_{c}$ in Eq. (28) is related to the established nonlinear contact force model. So the nonlinear dynamic characteristic model of the shift manipulator for robot driver is described by Eq. (28).

Since the displacement and velocity constraint equations of the shift manipulator are not included in Eq. (28), the constraints are easily violated in the process of numerical calculation. So the kinematics and velocity constraint equations are only satisfied in the first integration step. The Baumgarte constraint default stability method is used commonly as.

$$
\boldsymbol{\Phi}_{q} \ddot{\boldsymbol{q}}-\boldsymbol{\xi}+2 \alpha \dot{\boldsymbol{\Phi}}+\beta^{2} \boldsymbol{\Phi}=\mathbf{0}
$$

Therefore, the stable dynamic equation of the shift manipulator after modification is obtained as

$$
\left[\begin{array}{cc}
\boldsymbol{M} & \boldsymbol{\Phi}_{q}^{T} \\
\boldsymbol{\Phi}_{q} & \boldsymbol{0}
\end{array}\right]\left[\begin{array}{l}
\ddot{\boldsymbol{q}} \\
\lambda
\end{array}\right]=\left[\begin{array}{c}
\boldsymbol{g}+\boldsymbol{g}_{c} \\
\boldsymbol{\xi}-2 \alpha \dot{\boldsymbol{\Phi}}-\beta^{2} \boldsymbol{\Phi}
\end{array}\right]
$$

where $\dot{\boldsymbol{\Phi}}=\partial \boldsymbol{\Phi} / \partial t, \alpha$ and $\beta$ are Baumgarte correction factor and $\alpha>0, \beta>0$.

The active joints driving torque is related to $\boldsymbol{g}+\boldsymbol{g}_{c}$. So based on the Lagrangian dynamic equation, the active joints driving torque is obtained as

$$
\left\{\begin{array}{l}
T_{21}=\frac{\partial}{\partial t}\left(\frac{\partial L}{\partial \dot{\theta}_{21}}\right)-\frac{\partial L}{\partial \theta_{21}} \\
T_{31}=\frac{\partial}{\partial t}\left(\frac{\partial L}{\partial \dot{\theta}_{31}}\right)-\frac{\partial L}{\partial \theta_{31}}
\end{array}\right.
$$

where $L$ is Lagrangian function of the shift manipulator.

By solving Eq. (30), the end displacement error of the shift manipulator is obtained as

$$
\left\{\begin{array}{l}
\Delta x_{p}=\frac{\partial x_{p}}{\partial l_{11}} \Delta l_{11}+\frac{\partial x_{p}}{\partial l_{12}} \Delta l_{12}+\frac{\partial x_{p}}{\partial \theta_{11}} \Delta \theta_{11}+\frac{\partial x_{p}}{\partial \theta_{12}} \Delta \theta_{12} \\
\Delta y_{p}=\frac{\partial y_{p}}{\partial l_{11}} \Delta l_{11}+\frac{\partial y_{p}}{\partial l_{12}} \Delta l_{12}+\frac{\partial y_{p}}{\partial \theta_{11}} \Delta \theta_{11}+\frac{\partial y_{p}}{\partial \theta_{12}} \Delta \theta_{12}
\end{array}\right.
$$

By differentiating Eq. (31), the end velocity and acceleration are obtained as 


$$
\begin{aligned}
& \left\{\begin{array}{l}
\Delta v_{p x}=\frac{\partial v_{p x}}{\partial l_{11}} \Delta l_{11}+\frac{\partial v_{p x}}{\partial l_{12}} \Delta l_{12}+\frac{\partial v_{p x}}{\partial \theta_{11}} \Delta \theta_{11}+\frac{\partial v_{p x}}{\partial \theta_{12}} \Delta \theta_{12}+\frac{\partial v_{p x}}{\partial \dot{\theta}_{11}} \Delta \dot{\theta}_{11}+\frac{\partial v_{p x}}{\partial \dot{\theta}_{12}} \Delta \dot{\theta}_{12} \\
\Delta v_{p y}=\frac{\partial v_{p y}}{\partial l_{11}} \Delta l_{11}+\frac{\partial v_{p y}}{\partial l_{12}} \Delta l_{12}+\frac{\partial v_{p y}}{\partial \theta_{11}} \Delta \theta_{11}+\frac{\partial v_{p y}}{\partial \theta_{12}} \Delta \theta_{12}+\frac{\partial v_{p y}}{\partial \dot{\theta}_{11}} \Delta \dot{\theta}_{11}+\frac{\partial v_{p y}}{\partial \dot{\theta}_{12}} \Delta \dot{\theta}_{12}
\end{array}\right. \\
& \left\{\begin{array}{l}
\Delta a_{p x}=\frac{\partial a_{p x}}{\partial l_{11}} \Delta l_{11}+\frac{\partial a_{p x}}{\partial l_{12}} \Delta l_{12}+\frac{\partial a_{p x}}{\partial \theta_{11}} \Delta \theta_{11}+\frac{\partial a_{p x}}{\partial \theta_{12}} \Delta \theta_{12}+\frac{\partial a_{p x}}{\partial \dot{\theta}_{11}} \Delta \dot{\theta}_{11}+\frac{\partial a_{p x}}{\partial \dot{\theta}_{12}} \Delta \dot{\theta}_{12}+\frac{\partial a_{p x}}{\partial \ddot{\theta}_{11}} \Delta \ddot{\theta}_{11}+\frac{\partial a_{p x}}{\partial \ddot{\theta}_{12}} \Delta \ddot{\theta}_{12} \\
\Delta a_{p y}=\frac{\partial a_{p y}}{\partial l_{11}} \Delta l_{11}+\frac{\partial a_{p y}}{\partial l_{12}} \Delta l_{12}+\frac{\partial a_{p y}}{\partial \theta_{11}} \Delta \theta_{11}+\frac{\partial a_{p y}}{\partial \theta_{12}} \Delta \theta_{12}+\frac{\partial a_{p y}}{\partial \dot{\theta}_{11}} \Delta \dot{\theta}_{11}+\frac{\partial a_{p y}}{\partial \dot{\theta}_{12}} \Delta \dot{\theta}_{12}+\frac{\partial a_{p y}}{\partial \ddot{\theta}_{11}} \Delta \ddot{\theta}_{11}+\frac{\partial a_{p y}}{\partial \ddot{\theta}_{12}} \Delta \ddot{\theta}_{12}
\end{array}\right.
\end{aligned}
$$

\section{Simulation analysis and test verification}

The shift manipulator for robot driver is a seven-link two-degree-of-freedom parallel mechanism, so the influence of the size of clearance joint on the nonlinear dynamic characteristics of the shift manipulator need to be analyzed. The simulation analysis is conducted based on the established dynamic characteristic model. The structural parameters of the shift manipulator including size parameters, centroid position parameters, quality parameters and inertia parameters are shown in Table 1. The key simulation parameters of the shift manipulator during the shifting process are shown in Table 2.

Table 1 Structural parameters of the shift manipulator

\begin{tabular}{cccccccc}
\hline \multicolumn{2}{c}{ Size $(\mathrm{mm})$} & \multicolumn{2}{c}{ Centroid position $(\mathrm{mm})$} & \multicolumn{2}{c}{ Quality $(\mathrm{kg})$} & \multicolumn{2}{c}{ Moment of inertia $\left(\mathrm{kg} \cdot \mathrm{m}^{2}\right)$} \\
\hline$l_{11}$ & 180 & $r_{11}$ & 88 & $m_{11}$ & 0.315 & $I_{11}$ & $1.019 \times 10-3$ \\
$l_{12}$ & 120 & $r_{12}$ & 68 & $m_{12}$ & 0.694 & $I_{12}$ & $5.034 \times 10-3$ \\
$l_{21}$ & 120 & $r_{21}$ & 51 & $m_{21}$ & 0.242 & $I_{21}$ & $4.716 \times 10-4$ \\
$l_{22}$ & 230 & $r_{22}$ & 115 & $m_{22}$ & 0.39 & $I_{22}$ & $1.909 \times 10-3$ \\
$l_{31}$ & 230 & $r_{31}$ & 106 & $m_{31}$ & 0.422 & $I_{31}$ & $2.383 \times 10-3$ \\
$l_{32}$ & 120 & $r_{32}$ & 60 & $m_{32}$ & 0.21 & $I_{32}$ & $3.214 \times 10-4$ \\
$l_{p c}$ & 480 & $r_{p c}$ & 260 & $m_{p c}$ & 2.81 & $I_{p c}$ & 0.161 \\
\hline
\end{tabular}

\begin{tabular}{|c|c|c|c|}
\hline Parameter & Value & Parameter & Value \\
\hline $\begin{array}{l}\text { Restitution coefficient } \\
c_{e}\end{array}$ & 0.9 & $\begin{array}{l}\text { Maximum critical } \\
\text { velocity } v_{d}\end{array}$ & $100 \mathrm{~mm} / \mathrm{s}$ \\
\hline Young's modulus $E$ & 207GP & Integration step & 0.0001 \\
\hline Poisson ratio $v$ & 0.3 & Relative error & 0.00001 \\
\hline Friction coefficient $c_{f}$ & 0.5 & Simulation time & $8.4 \mathrm{~s}$ \\
\hline Baumgarte $\alpha$ & 5 & Clearance position & $\mathrm{B} 1, \mathrm{~B} 2, \mathrm{~B} 3, \mathrm{C} 2, \mathrm{C} 3$ \\
\hline Baumgarte $\beta$ & 5 & Clearance number & single, double, full \\
\hline $\begin{array}{l}\text { Minimum critical } \\
\text { velocity } v_{s}\end{array}$ & $1 \mathrm{~mm} / \mathrm{s}$ & Clearance size & $\begin{array}{c}0.05 \mathrm{~mm}, \quad 0.1 \mathrm{~mm} \\
0.5 \mathrm{~mm}\end{array}$ \\
\hline
\end{tabular}

Table 2 Key simulation parameters of the shift manipulator during the shifting process

5.1 The nonlinear dynamic characteristic effect of the size of clearance joint

In order to analyze the influence of different sizes of clearance joints on the dynamic characteristics of the shift manipulator for robot driver in selection and gear 
direction, the dynamic simulations are conducted through different sizes of clearance joints of the shift manipulator. In the simulation process, the shift manipulator is set to full clearance joints and the sizes of clearance joints are set to $0.05 \mathrm{~mm}, 0.1 \mathrm{~mm}$ and $0.5 \mathrm{~mm}$. The influence of different sizes of clearance joints on the dynamic characteristics of the shift manipulator including the end displacement, velocity, acceleration and active joint driving torque is compared.

The influence of the end displacement error of the shift manipulator is shown in Fig.5. The extreme values of the displacement error of the end of the shift manipulator in selection and gear direction under different sizes of clearance joints are shown in Table 3. The influence of the end velocity of the shift manipulator is shown in Fig.6. The influence of the end acceleration of the shift manipulator is shown in Fig.7. The influence of the active joint driving torque of the shift manipulator is shown in Fig.8.

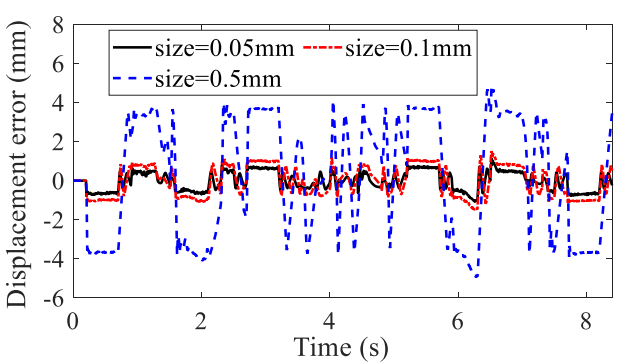

(a)

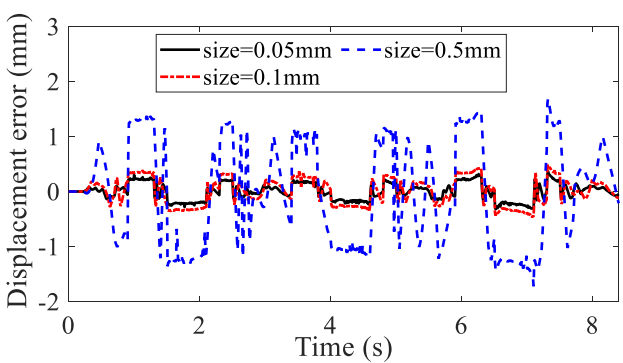

(b)

Fig. 5 The influence of the end displacement error: a selection direction, b gear direction

Table 3 Extreme values of the displacement error of the end of the shift manipulator

\begin{tabular}{ccc}
\hline $\begin{array}{c}\text { Size of clearance } \\
\text { joint }\end{array}$ & Extreme values in selection direction & Extreme values in gear direction \\
\hline $0.05 \mathrm{~mm}$ & $1.12 \mathrm{~mm}$ & $0.26 \mathrm{~mm}$ \\
$0.1 \mathrm{~mm}$ & $1.43 \mathrm{~mm}$ & $0.49 \mathrm{~mm}$ \\
$0.5 \mathrm{~mm}$ & $4.98 \mathrm{~mm}$ & $1.61 \mathrm{~mm}$ \\
\hline
\end{tabular}

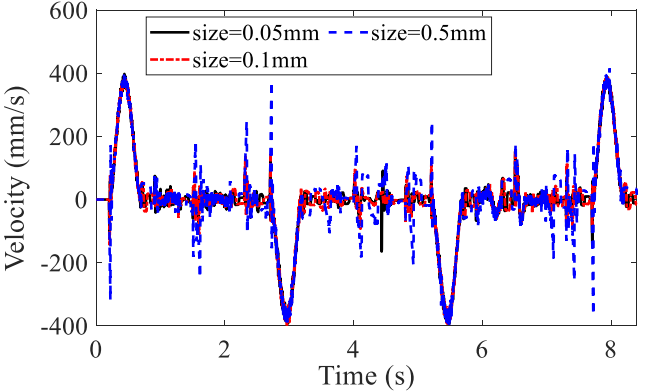

(a)

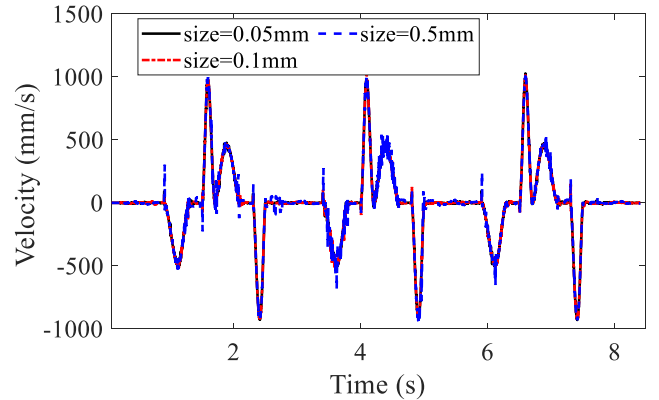

(b)

Fig. 6 The influence of the end velocity: a selection direction, $\mathbf{b}$ gear direction 


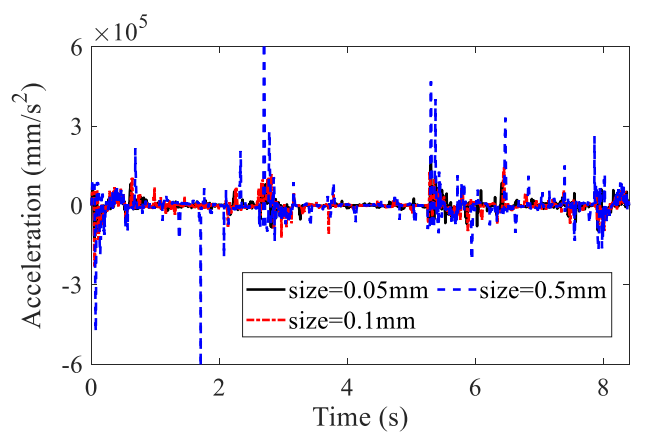

(a)

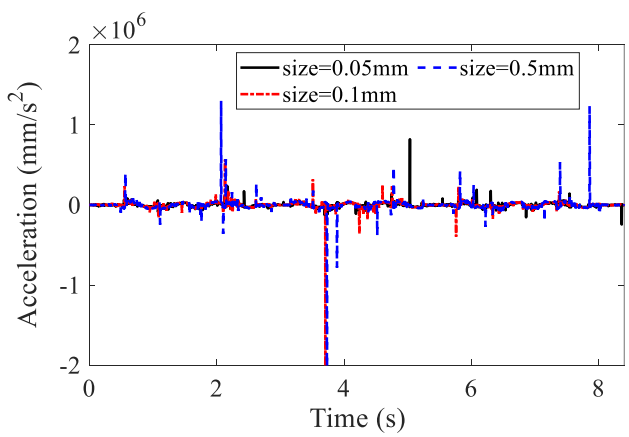

(b)

Fig. 7 The influence of the end acceleration: a selection direction, $\mathbf{b}$ gear direction

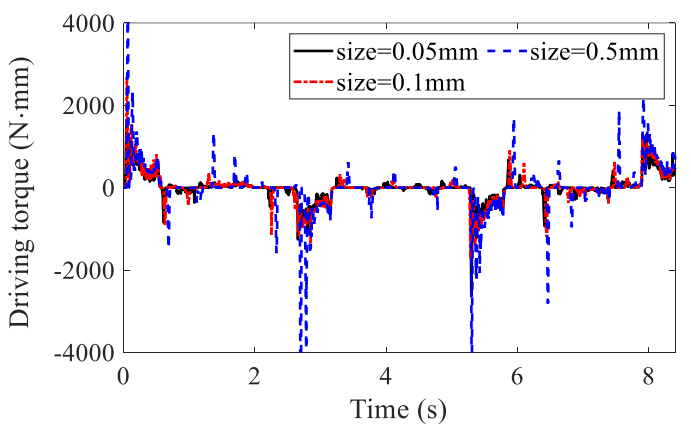

(a)

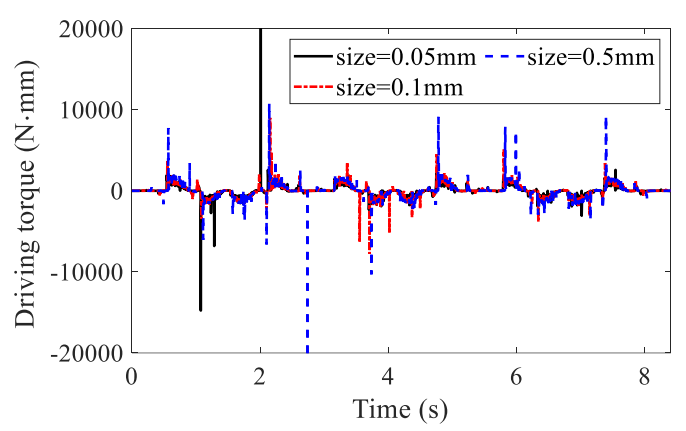

(b)

Fig. 8 The influence of the active joint driving torque: a selection direction, b gear direction

As is seen in Fig.5, the end displacement error of the shift manipulator in two directions are greatly affected by different sizes of clearance joints. Table 3 shows that the influence of the end displacement error of the shift manipulator in selection direction is much greater than gear direction. The end displacement error of the shift manipulator is still within the design requirement $\pm 2 \mathrm{~mm}$ when the size of clearance joint is less than $0.1 \mathrm{~mm}$. While the end displacement error of the shift manipulator exceeds $2 \mathrm{~mm}$ when the size of clearance joint is between $0.1 \mathrm{~mm}$ and $0.5 \mathrm{~mm}$, meaning that the characteristic requirement is not achieved.

As is seen in Fig.6, Fig.7 and Fig.8, the end velocity, acceleration and active joint driving torque of the shift manipulator are affected by different sizes of clearance joints both in selection direction and gear direction. The curve fluctuates more violently and the peak value is larger as the clearance joint increases.

In short, the existence of clearance joints has an important impact on the nonlinear dynamic characteristics of the shift manipulator. The dynamic characteristics of the shift manipulator including the end displacement, velocity, acceleration and active joint driving torque become worse as the size of clearance joint increases. Especially when the size of clearance joint of the shift manipulator reaches $0.5 \mathrm{~mm}$, the end displacement error exceeds the design requirements. Therefore, it is necessary to strictly control the size of clearance joint of the shift manipulator, otherwise the shift operation is failure caused by the clearance joints.

\subsection{The performance test of the shift manipulator}

In order to verify the effectiveness of the established nonlinear dynamic characteristic model of the shift manipulator for robot driver, The Changan Yuexiang with manual transmission is conducted in a long-term emission durability 
$\mathrm{V}$-type test under the operation of robot driver. The test is conducted on the BOCO NJ150/80 chassis dynamometer of the National Bus Quality Supervision and Inspection Center, the site picture of emission durability test is shown in Fig.9. The parameters of test vehicle are shown in Table 4. The shift manipulator for robot driver is installed in the test vehicle. The shift handle is manipulated by the shift manipulator to test the shift performance. The force sensor and the speed sensor are installed at the connection between the shift manipulator and the shift handle, and force and speed in gear direction are collected in real time during the shift process.

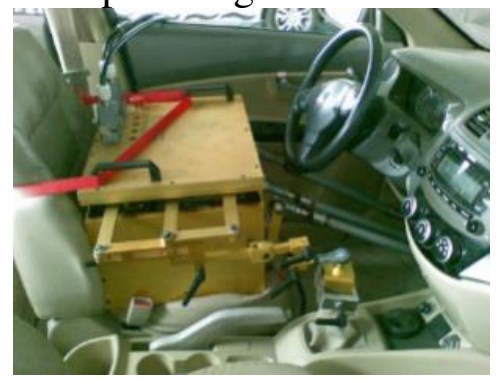

(a)

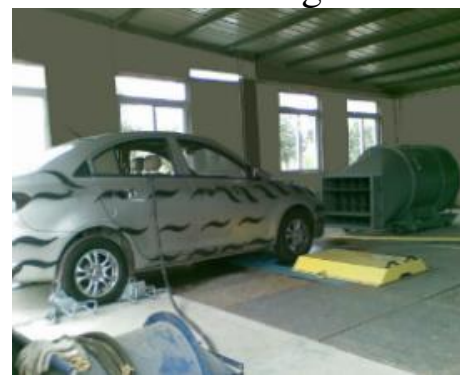

(b)

Fig. 9 The site picture of emission durability test: a robot driver installed on the test vehicle, $\mathbf{b}$ test site

Table 4 The parameters of test vehicle

\begin{tabular}{ccccc}
\hline Model of vehicle & $\begin{array}{c}\text { Engine } \\
\text { parameters }\end{array}$ & Drive method & Gear & $\begin{array}{c}\text { Transmission } \\
\text { ratio }\end{array}$ \\
\hline & Displacement & & 1st gear & 3.58 \\
Changan & 1.5L, & & 2nd gear & 1.92 \\
Yuexiang & 4-cylinder 4- & Front & 3rd gear & 1.28 \\
& stroke, & Predecessor & 4th gear & 0.95 \\
& water-cooled, & & 5th gear & 0.76 \\
\hline
\end{tabular}

The comparative analysis including test curve of shift displacement and shift speed, simulation curve of shift manipulator with and without clearance joints are conducted after the test. The diagrams of the process of shift manipulator from second gear to third gear are shown in Fig.10. The diagrams of the process of shift manipulator from fourth gear to fifth gear are shown in Fig.11.

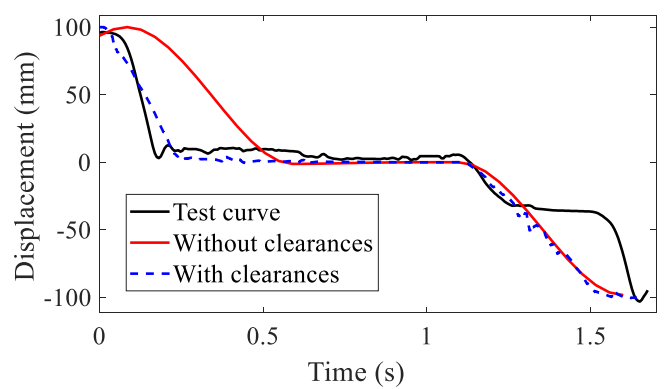

(a)

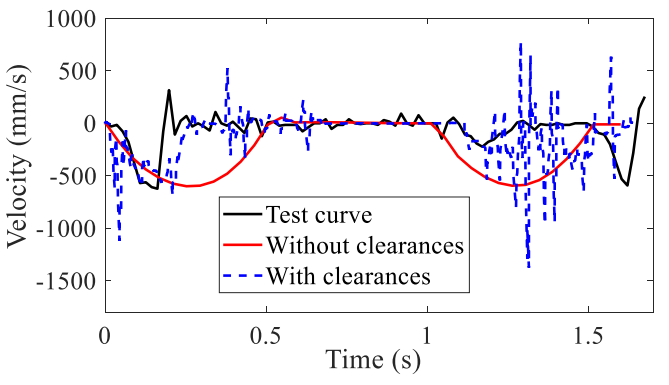

(b) 


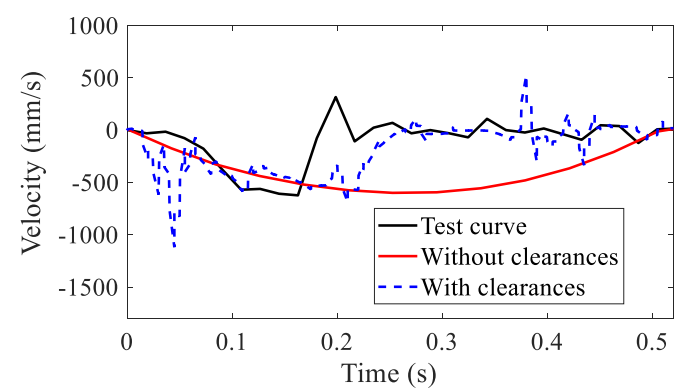

(c)

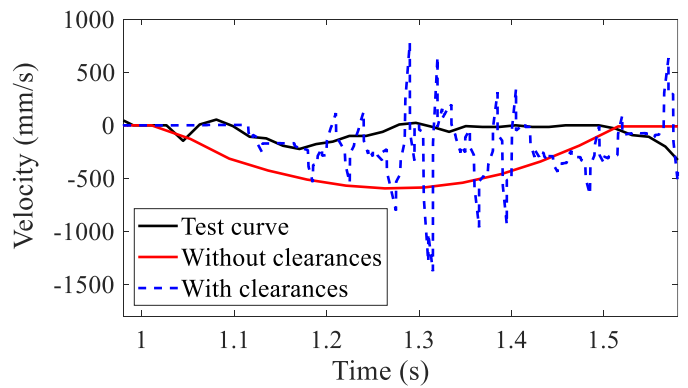

(d)

Fig. 10 The process of shift manipulator from second gear to third gear: a displacement curve, b velocity curve, $\mathbf{c}$ enlarged velocity diagram of back gear, $\mathbf{d}$ enlarged velocity diagram of forward gear

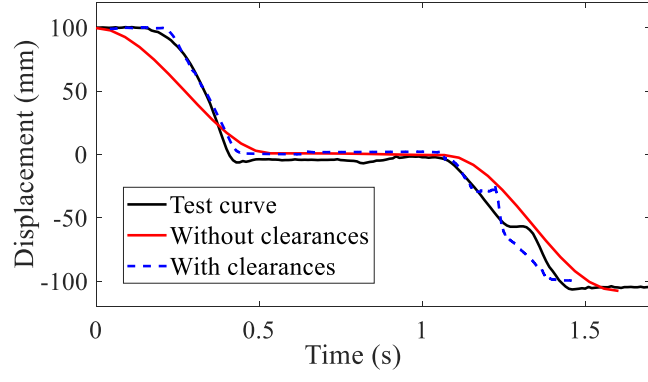

(a)

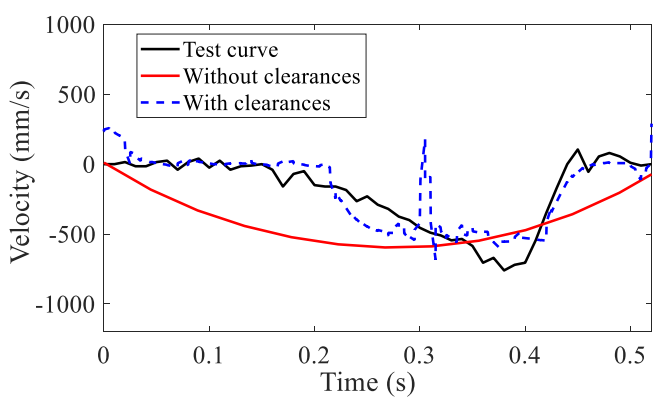

(c)

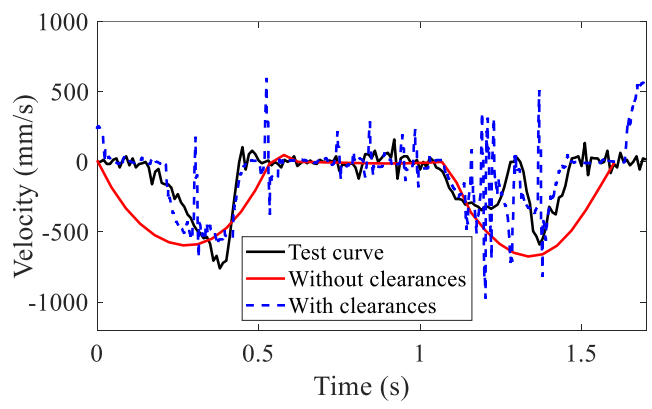

(b)

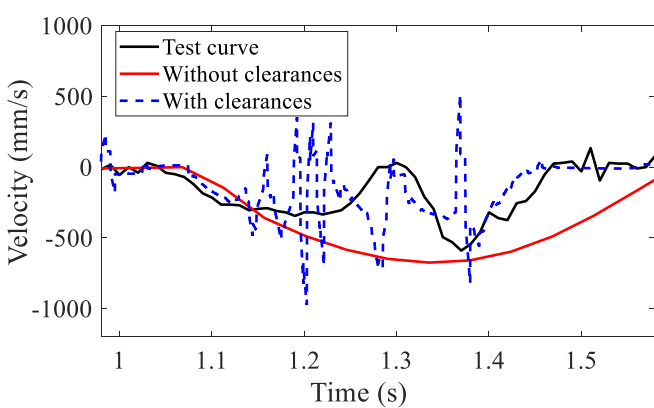

(d)

Fig. 11 The process of shift manipulator from fourth gear to fifth gear: a displacement curve, b velocity curve, $\mathbf{c}$ enlarged velocity diagram of back gear, $\mathbf{d}$ enlarged velocity diagram of forward gear

As is seen in Fig.10(a), the shift handle is manipulated from second gear to neutral gear and then from neutral gear to third gear through the shift manipulator. The curve of displacement with clearance is closer to the test curve compared with the simulation result without clearance. Fig.10(b)shows that the curve of velocity with clearance fluctuates obviously than the test curve, which caused by collision between bushing and pin in clearance joints. Fig.10(c) shows that the trend of the velocity curve with clearance and the test curve is in good agreement in the process of retreating. Fig.10(d) shows that the simulation curve fluctuates more than the test curve, but the general trend is the same.

As is seen in Fig.11, the shift handle is manipulated from fourth gear to neutral gear and then from neutral gear to fifth gear through the shift manipulator. The analysis of fourth gear to fifth gear is similar to the analysis of second gear to third gear. The curves of displacement and velocity with clearance is closer to the test curves compared with the simulation results without clearance. However, as is seen 
in Fig.11(c) and Fig.11(d), the difference from the previous analysis is that the curve of velocity with clearance is closer to the test curve and the error is smaller both in the process of back gear and advance gear.

In short, compared with the curves of shift manipulator without clearance joints, the fluctuation trend of the simulation curves with clearance joints and the test curves is the same. So it is seen that the nonlinear dynamic characteristics are well analyzed and verified on the basis of the presented dynamic characteristic model with full revolute clearance joint.

\section{Conclusions}

A nonlinear dynamic model for characteristic analysis of the shift manipulator for robot driver is presented in this paper. Multiple revolute clearance joints are considered in presented model to improve dynamic characteristics.

Firstly, the relative penetration depth and velocity are obtained based on the kinematic model of clearance joint for the shift manipulator. The contact force of clearance joint in the shift manipulator is analyzed through contact force model and friction model. By introducing full revolute clearance joints, the nonlinear dynamic characteristic model of the shift manipulator is established. The comparative analysis of dynamic equations for the shift manipulator with and without clearance joints. The results show that the existence of clearance joints has an important impact on the nonlinear dynamic characteristics of the shift manipulator.

Besides, the nonlinear dynamic characteristic laws of the shift manipulator are analyzed based on the presented model. The comparative analysis of dynamic characteristics of the shift manipulator under different sizes of clearance joints is conducted. And the performance test of the shift manipulator is conducted to verify the validity of the presented dynamic characteristic model The results show that the nonlinear dynamic characteristics are well analyzed and verified on the basis of the presented dynamic characteristic model with full revolute clearance joint.

Future work will develop joint lubrication and link flexibility according to the presented characteristic model. It will also concern the application of this model to the mechanical legs for the robot driver.

\section{Declarations}

\section{Funding}

This study was funded by the National Natural Science Foundation of China (NSFC); the Fundamental Research Funds for the Central Universities (NRFCU); and the Six Talents Peak Project of Jiangsu Province (STPPJP).

\section{Competing interests}

The authors declare that they have no competing interests.

\section{Availability of data and material}

Not applicable.

\section{Code availability}


Not applicable.

\section{Authors' contributions}

Chen developed and tested the robot driver, analyzed the data, and wrote this manuscript. $\mathrm{Xu}$ established the characteristic model, conducted the dynamic analysis, and wrote this manuscript. Both authors read and approved the final manuscript.

\section{Ethics approval}

Not applicable.

\section{Consent to participate}

Not applicable.

\section{Consent for publication}

Not applicable.

\section{Acknowledgements}

This work is supported by the National Natural Science Foundation of China (Grant No. 51675281); the Fundamental Research Funds for the Central Universities (Grant No. 30918011101); the Six Talents Peak Project of Jiangsu Province (Grant 2015-JXQC-003).

\section{References}

1. Chen, G., Zhang, W.G.: Hierarchical Coordinated Control Method for Unmanned Robot Applied to Automotive Test. IEEE Transactions on Industrial Electronics. 63(2), 10391051 (2016). https://doi.org/10.1109/tie.2015.2477266

2. Chen, G., Zhang, W.G.: Digital Prototyping Design of Electromagnetic Unmanned Robot Applied to Automotive Test. Robotics and Computer-Integrated Manufacturing. 32, 5464 (2015). https://doi.org/10.1016/j.rcim.2014.09.004

3. Sailer, S., Buchholz, M., Dietmayer, K.: Driveaway and braking control of vehicles with manual transmission using a robotic driver. IEEE International Conference on Control Applications. Hyderabad, India, 235-240 (2013). https://doi.org/10.1109/cca.2013.6662764

4. Huang, X., Zhang, S., Peng, H.: Developing Robot Driver Etiquette Based on Naturalistic Human Driving Behavior. IEEE Transactions on Intelligent Transportation Systems. 21 (4), 1393-1403 (2020). https://doi.org/10.1109/tits.2019.2913102

5. Alt, B., Hermann, E., Svaricek, F.: Second order sliding modes control for rope winch based automotive driver robot. International Journal of Vehicle Design. 62 (2/3/4), 147164 (2013), https://doi.org/10.1504/ijvd.2013.052707

6. Zhu, Y.H., Fu, Z.Y., Fu, Z., Chen, X., Wu, Q.: Multi-features fusion for fault diagnosis of pedal robot using time-speed signals. Sensors. 19 (1), 163 (2019), https://doi.org/10.3390/s19010163

7. Hirata, N., Mizutani, N., Matsui, H., Yano, K., Takahashi, T.: Fuel consumption in a driving test cycle by robotic driver considering system dynamics. 2015 IEEE International Conference on Robotics and Automation (ICRA). Seattle, WA, USA, 3374-3379 (2015), https://doi.org/10.1109/icra.2015.7139665.

8. Yechiel, O., Guterman, H.: IVO Robot Driver. 2016 IEEE 84th Vehicular Technology Conference (VTC-Fall). Montreal, QC, 1-5 (2016), https://doi.org/10.1109/vtcfall.2016.7881054 
9. Chen, G., Zhang, W.G., Yu, B.: Multibody dynamics modeling of electromagnetic directdrive vehicle robot driver. International Journal of Advanced Robotic Systems. 14(5), (2017), https://doi.org/10.1177/1729881417731896

10. Lu, W., Chen, H., Wang, L.: Motion Analysis of Tractor Robot Driver's Gear Shift Mechanical Arm. Transactions of the Chinese Society for Agricultural Machinery. 47(1), 37-44 (2016), https://doi.org/10.6041/j.issn.1000-1298.2016.01.006

11. Yu, S.L., Chen, G.: Rigid-flexible Coupling Kinematics Analysis of Shifting Manipulator for Robot Driver. Automotive Engineering. 40(6), 733-740 (2018), https://doi.org/10.19562/j.chinasae.qcgc.2018.06.017

12. Mizutani, N., Ishida, Y., Matsui, H., Yano, K., Takahashi, T.: Automatic driving control by robotic driver considering the lack of a driving force at changing gears. IEEE/RSJ International Conference on Intelligent Robots and Systems (IROS). Daejeon, Korea (South), 3075-3080 (2016), https://doi.org/10.1109/iros.2016.7759476

13. Chu, C.C., Wang, D., Zhang, W.G., Xu, T.: Speed control of electric vehicle driving robot based on inverse control strategy model. Automotive Engineering. 42(09), 1166-1173 (2020), https://doi.org/10.19562/j.chinasae.qcgc.2020.09.004

14. Zhou, N., Chen, G.: Dynamic analysis of gear shifting manipulator based on neural network load fluctuation simulation. China Mechanical Engineering. 31(4), 472-481 (2020), https://doi.org/10.3969/j.issn.1004-132X.2020.04.015

15. Yu, L.Y., Zheng, S., Chang, J.H., Liu, X.X.: Pedal Actuator of Driver Robot Based on Flexible Manipulator. ASME International Design Engineering Technical Conferences and Computers and Information in Engineering Conference (IDETC/CIE). Cleveland, Ohio, USA, (2017), https://doi.org/10.1115/DETC2017-68100

16. Wu, X.Z.: Dynamic analysis of the double crank mechanism with a 3D translational clearance joint employing a variable stiffness contact force model. Nonlinear Dynamics. 99(5), 1937-1958 (2020), https://doi.org/10.1007/s11071-019-05419-2

17. Qian, M.B., Qin, Z., Yan, S.Z., Zhang, L.: A comprehensive method for the contact detection of a translational clearance joint and dynamic response after its application in a crank-slider mechanism. Mechanism and Machine Theory. 145, (2020), https://doi.org/10.1016/j.mechmachtheory.2019.103717

18. Zhang, H.D., Zhang, X.M., Zhang, X.C., Mo, J.S.: Dynamic analysis of a 3- P RR parallel mechanism by considering joint clearances. Nonlinear Dynamics. 90(1), 405-423 (2017), https://doi.org/10.1007/s11071-017-3672-1

19. Lv, T.Q., Zhang, Y.Q., Duan, Y.P., Yang, J.: Kinematics \& compliance analysis of double wishbone air suspension with frictions and joint clearances. Mechanism and Machine Theory. 156, (2021), https://doi.org/10.1016/J.MECHMACHTHEORY.2020.104127

20. Xiang, W.W.K., Yan, S.Z., Wu, J.N., Niu, W.D.: Dynamic response and sensitivity analysis for mechanical systems with clearance joints and parameter uncertainties using Chebyshev polynomials method. Mechanical Systems and Signal Processing. 138, (2020), https://doi.org/10.1016/j.ymssp.2019.106596

21. Zhan, Z.H., Zhang, X.M., Zhang, H.D., Chen, G.C.: Unified motion reliability analysis and comparison study of planar parallel manipulators with interval joint clearance variables. Mechanism and Machine Theory. 138, 58-75 (2019), https://doi.org/10.1016/j.mechmachtheory.2019.03.041

22. Zhu, A.B., He, S.L., Zhao, J.W., Luo, W.C.: A nonlinear contact pressure distribution model for wear calculation of planar revolute joint with clearance. Nonlinear Dynamics. 88(1), 315-328 (2017), https://doi.org/10.1007/s11071-016-3244-9

23. Fang, C.C., Meng, X.H., Lu, Z.J., Wu, G., Tang, D.H., Zhao, B.: Modeling a lubricated full-floating pin bearing in planar multibody systems. Tribology International. 131, 222237 (2019), https://doi.org/ 10.1016/j.triboint.2018.10.045

24. Wang, Z., Tian, Q., Hu, H.Y., Flores, P.: Nonlinear dynamics and chaotic control of a flexible multibody system with uncertain joint clearance. Nonlinear Dynamics. 86(3), 1571-1597 (2016), https://doi.org/10.1007/s11071-016-2978-8

25. Li, Y.Y., Wang, C., Huang, W.H.: Dynamics analysis of planar rigid-flexible coupling deployable solar array system with multiple revolute clearance joints. Mechanical Systems and Signal Processing. 117, 188-209 (2019), https://doi.org/10.1016/j.ymssp.2018.07.037

26. Tian, Q., Flores, P., Lankarani, H.M.: A comprehensive survey of the analytical, numerical and experimental methodologies for dynamics of multibody mechanical systems with 
clearance or imperfect joints. Mechanism and Machine Theory. 122, 1-57 (2018), https://doi.org/ 10.1016/j.mechmachtheory.2017.12.002

27. Sun, D.Y., Shi, Y., Zhang, B.Q.: Robust optimization of constrained mechanical system with joint clearance and random parameters using multi-objective particle swarm optimization. Structural and Multidisciplinary Optimization. 58(5), 2073-2084 (2018), https://doi.org/10.1007/s00158-018-2021-4

28. Yang, Y.L., Cheng, J.J.R., Zhang, T.Q.: Vector form intrinsic finite element method for planar multibody systems with multiple clearance joints. Nonlinear Dynamics. 86(1), 421440 (2016), https://doi.org/10.1007/s11071-016-2898-7

29. Zheng, X.D., Zhang, F., Wang, Q.: Modeling and simulation of planar multibody systems with revolute clearance joints considering stiction based on an LCP method. Mechanism and Machine Theory. 130, 184-202 (2018), https://doi.org/10.1016/j.mechmachtheory.2018.08.017

30. Li, L., Zhu, X.J.: Design of compliant revolute joints based on mechanism stiffness matrix through topology optimization using a parameterization level set method. Structural and Multidisciplinary Optimization. 60(4), 1475-1489 (2019), https://doi.org/10.1007/s00158019-02278-8

31. Varedi, S.M., Daniali, H.M., Dardel, M., Fathi, A.: Optimal dynamic design of a planar slider-crank mechanism with a joint clearance. Mechanism and Machine Theory. 86, 191200 (2015), https://doi.org/10.1016/j.mechmachtheory.2014.12.008

32. Lai, X.M., He, H., Lai, Q.F., Wang, C., Yang, J.H., Zhang, Y., Fang, H.Y., Liao, S.R.: Computational prediction and experimental validation of revolute joint clearance wear in the low-velocity planar mechanism. Mechanical Systems and Signal Processing. 85, 963976 (2017), https://doi.org/10.1016/j.ymssp.2016.09.027

33. Chen, X.L., Gao, W.H., Deng, Y., Wang, Q.: Chaotic characteristic analysis of spatial parallel mechanism with clearance in spherical joint. Nonlinear Dynamics. 94(4), 26252642 (2018), https://doi.org/10.1007/s11071-018-4513-6

34. Erkaya, S., Doğan, S., Ulus, Ş.: Effects of joint clearance on the dynamics of a partly compliant mechanism: Numerical and experimental studies. Mechanism and Machine Theory. 88, 125-140 (2015), https://doi.org/10.1016/j.mechmachtheory.2015.02.007

35. Natsiavas, S.: Analytical Modeling of Discrete Mechanical Systems Involving Contact, Impact, and Friction. Applied Mechanics Reviews. 71(5), 050802 (2019), https://doi.org/10.1115/1.4044549

36. Khan, Z.A., Chacko, V., Nazir, H.: A review of friction models in interacting joints for durability design. Friction. 5, 1-22 (2017), https://doi.org/10.1007/s40544-017-0143-0

37. Chen, X.L., Jiang, S.A., Deng, Y., Wang, Q.: Dynamics analysis of 2-DOF complex planar mechanical system with joint clearance and flexible links. Nonlinear Dynamics. 93(3), 1009-1034 (2018), https://doi.org/10.1007/s11071-018-4242-x

38. Guo, J.N., He, P., Liu, Z.S., Huang, H.Y.: Investigation of an improved planar revolute clearance joint contact model with rough surface. Tribology International. 134, 385-393 (2019), https://doi.org/10.1016/j.triboint.2019.02.019

39. Zhao, Bo., Zhou, K., Xie, Y.B.: A new numerical method for planar multibody system with mixed lubricated revolute joint. International Journal of Mechanical Sciences. 113, 105-119 (2016), https://doi.org/10.1016/j.ijmecsci.2016.04.016

40. Wang, G.X., Wang, L.: Dynamics investigation of spatial parallel mechanism considering rod flexibility and spherical joint clearance. Mechanism and Machine Theory. 137, 83-107 (2019), https://doi.org/10.1016/j.mechmachtheory.2019.03.017

41. Tang, L.L., Liu, J.Y.: Modeling and analysis of sliding joints with clearances in flexible multibody systems. Nonlinear Dynamics. 94(4), 2423-2440 (2018), https://doi.org/10.1007/s11071-018-4500-y

42. Khashaba, U.A., Sebaey, T.A., Selmy, A.I.: Experimental verification of a progressive damage model for composite pinned-joints with different clearances. International Journal of Mechanical Sciences. 152, 481-491 (2019), https://doi.org/10.1016/j.ijmecsci.2019.01.023

43. Song, N.N., Peng, H.J., Xu, X.M., Wang, G.: Modeling and simulation of a planar rigid multibody system with multiple revolute clearance joints based on variational inequality. Mechanism and Machine Theory. 154, (2020), https://doi.org/10.1016/j.mechmachtheory.2020.104053 
44. Sun, D.Y., Zhang, B.Q., Liang, X.F., Shi, Y., Suo, B.: Dynamic analysis of a simplified flexible manipulator with interval joint clearances and random material properties. Nonlinear Dynamics. 98(2), 1049-1063 (2019), https://doi.org/10.1007/s11071-01905248-3

45. Zhao, B., Zhang, Z.N., Fang, C.C., Dai, X.D., Xie, Y.B.: Modeling and analysis of planar multibody system with mixed lubricated revolute joint. Tribology International. 98, 229241 (2016), https://doi.org/10.1016/j.triboint.2016.02.024

46. Ma, J., Qian, L.F.: Modeling and simulation of planar multibody systems considering multiple revolute clearance joints. Nonlinear Dynamics. 90(3), 1907-1940 (2017), https://doi.org/10.1007/s11071-017-3771-z

47. Pi, T., Zhang, Y.Q.: Simulation of planar mechanisms with revolute clearance joints using the multipatch based isogeometric analysis. Computer Methods in Applied Mechanics and Engineering. 343(1), 453-489 (2019), https://doi.org/10.1016/j.cma.2018.08.039 